subjects. It is important to carry out scans in such a way that maximum use can be made of data collected for research purposes ultimately aimed at benefiting the group of those with schizophrenia as a whole.

Currently at Oxford we are carrying out MRI on adolescents presenting with schizophrenia. This group is a good one for testing the neurodevelopmental hypothesis of the aetiology of schizophrenia. The research has been approved by our local Research Ethics Committee.

I would be grateful to be informed of subjects who might be suitable for this study. Only DSM-III R criteria are required. I have obtained a grant sufficient to cover the costs of research scans and travelling expenses. We have scanned 19 subjects so far and aim to carry out two further Saturday morning sessions scanning eight adolescents each time within the next few months.

Please write to me at the address below or telephone 0227462733.

Department of Child and Family Psychiatry

51 London Road

Canterbury, Kent

CT2 8LF

\section{An MP questioning clinical judgement}

DeAr SiRS

A curious incident happened while I was a senior house officer in old age psychiatry. An 87-year-old lady had been admitted informally to the assessment ward from a residential home. She had been increasingly aggressive and restless, and had threatened to jump out of a window. She had biological features of depression, was not eating or sleeping, had lost a lot of weight, and expressed a wish to end her life.

After admission she remained retarded and there was concern about her fluid intake, amounting to less than a litre over three days. A course of ECT was arranged, and her legal next-of-kin, her daughter, was informed. Subsequently I received two threatening phone calls from her son-in-law, who was a consultant in one of the London teaching hospitals, saying that if we gave his mother-in-law ECT he would institute legal proceedings against myself, my consultant and the health authority.

At this time, the patient's daughter, to the best of my knowledge, had not expressed any reservations about our proposed course of action. When contacted, all she would say was that she needed time to discuss the matter with her husband. That evening I received a phone call from their Member of Parliament stating that he had been informed of his constituents' concern and associating himself with the threat of legal action.

In my two years in psychiatry, I have had instances of relatives being concerned about proposed courses of treatment, but to the best of my knowledge neither I nor any of my colleagues have ever received a phone call from an MP questioning our clinical judgement. I wondered if other readers have had any similar experience.

The patient died from an intestinal obstruction; she had had one session of ECT.

\section{Silkstream Unit \\ Colindale Hospital \\ London NW9 5 HG}

A. AkINKunm

\section{Involvement in patient care by managerial staff}

\section{DeAr Sirs}

I read the letter from Ali \& Evans (Psychiatric Bulletin, 1992, 16, 661) several times, with some bemusement, and then decided it must be a rather clever and amusing spoof on trends in 'community' psychiatry. That this is so can be seen by substituting day surgery centre for day hospital and wart for references to anxiety at interviews; the absurdity of the clinical arrangements described can then be clearly seen. However, perhaps I have missed something, or worse, the letter is not a spoof, and there is a real need to be more explicit - with the question, should not interview training of the type described be part of any psychiatric day hospital service when required?

\section{Birch Hill Hospital Rochdale OL129QB}

D. M. BOWKER

\section{Reply}

\section{DeAR SIRS}

Dr Bowker's analogy of a patient with a wart attending a surgical day hospital is inappropriate. Anxiety at a forthcoming interview was not our patient's presenting complaint; subclinical anorexia nervosa and social phobia were the reasons for referral. The other flaw in the analogy is to assume that a hospital administrator would possess the skills to treat his patient's wart. In fact, our administrator's training and experience in interviewing was the skill employed as an adjunct to treatment.

Our patient's problems were treated over two years with relaxation therapy and anxiety management, supportive psychotherapy aimed at raising self-esteem and assertiveness, as well as art therapy. Only recently during her attendance at our day hospital did the offer of an interview arise, bringing with it associated anxiety. It was due to the initiative shown by the Sister of the psychiatric day hospital who was aware of the administrator's experience, that the mock interviews were arranged. 